\title{
Memoriais e narrativas na formação de educadores da saúde: escritas de si, acompanhamento e mediação biográfica
}

\section{Memorials and narratives in the training of health educators: writing about oneself, monitoring and biographical mediation}

\author{
Alessandra Martins dos Reis* \\ Elizeu Clementino de Souza*
}

\begin{abstract}
RESUMO
As narrativas de educadores da saúde configuram-se como dispositivo que favorece a compreensão de aprendizagens experienciais no espaço formativo da Pós-Graduação em Educação na Saúde. Seu contexto de inserção são as Residências em Saúde, espaços de formação que integram o ensino e os serviços do Sistema Único de Saúde (SUS) no Brasil. Ancorados em princípios da pesquisa (auto)biográfica e na utilização de memoriais, objetiva-se discutir questões relacionadas ao processo de acompanhamento, suas interfaces com as escritas de si e as disposições de investigação-formação mobilizadas pela escrita de memoriais de três educadores no campo da formação em saúde, na condição de preceptores no Programa de Residências da Fundação Estatal Saúde da Família (FESF-SUS) na Bahia. As experiências de cuidado e de educação em equipes multiprofissionais são colocadas em reflexão nos memoriais de formação de educadores da saúde como processo de mediação do vivido e das relações entre formador e formandos, por meio das narrativas de experiências, com ênfase no desenvolvimento pessoal e profissional no contexto da formação em saúde.
\end{abstract}

Palavras-chave: Pesquisa (Auto)biográfica. Memoriais. Saúde. Formação. Educadores.

*Universidade do Estado da Bahia, Salvador, Bahia, Brasil. E-mail: alemreis@hotmail.com http://orcid.org/0000-0003-3508-3881 E-mail: esclementino@uol.com.br - http://orcid.org/00000002-4145-1460 


\begin{abstract}
The narratives of health educators are configured as a device that favors the understanding of experiential learning in the formative space of graduate studies in Health Education. Its context of insertion is Health Residencies, training spaces that integrate the teaching and services of the Unified Health System (known as SUS) in Brazil. Based on principles of the (auto) biographical research and in the use of memorials, the objective is to discuss issues related to the monitoring process, its interfaces with the writing about oneself, and the investigation-training provisions mobilized by writing the memorials of three educators in the field of Health Education, as preceptors in the Residency Program of the State Foundation for Family Health (Fundação Estatal Saúde da Família - FESF-SUS) in Bahia. The experiences of care and education in multi-professional teams are reflected in memorials for the training of health educators, as a process of mediation of what was experienced, and of the relationships between trainer and trainees, through the narratives of experiences with an emphasis on personal and professional development in the context of Health training.
\end{abstract}

Keywords: (Auto)Biographical research. Memorials. Health. Training. Educators.

\title{
Narrar a vida e pensar a profissão: indicando pistas
}

O texto insere-se na área da educação e da saúde e busca discutir questões sobre narrativas e escritas de si em memoriais de formação inscritas nas experiências de educadores da saúde, considerando o contexto de sua produção, o processo de autoria, de acompanhamento da escrita, sua forma textual e o seu conteúdo. Compreendemos, conforme sistematiza Souza (2014), que as narrativas possibilitam momentos de formação, implicando movimentos de reflexividade, de processos identitários individual e coletivo, de tomada de consciência sobre sua própria história, possibilitando aos sujeitos em formação reelaborarem acontecimentos cotidianos, transformando-os em aprendizagens experenciais.

A atividade de narrar e refletir sobre as experiencias a partir das suas perspectivas sobre o contexto, sobre as pessoas que se relacionam e, especialmente, sobre como se percebem nessa relação com o contexto e as pessoas, fez com que os memoriais de formação emergissem de uma escrita implicada e de interpretação da realidade, a partir do olhar de educadores da saúde inseridos na pós-graduação em educação na saúde. Centramos nossa atenção e análise nos memoriais produzidos no ano de 2017 por uma cirurgiã 
dentista, um enfermeiro e um professor de Educação Física, na condição de preceptores no Programa de Residências da Fundação Estatal Saúde da Família (Fesf-SUS) na Bahia, no contexto do curso de especialização em Educação na Saúde para Preceptoria no Sistema Único de Saúde (SUS).

Compreendemos a escrita como um dispositivo de investigação-formação no campo da pesquisa auto(biográfica), na medida em que as narrativas contidas em memoriais desvelam-se como oportunidade de formação para os educadores, possibilitando-os revisitarem suas memórias e trajetórias de vida-profissão em conexão com a formação, suas motivações para o ingresso na preceptoria e as possibilidades de formação pessoal e profissional reatualizadas no movimento refletivo relacionadas aos contextos, às práticas e aos desafios do exercício profissional na condição de educador em saúde.

A pesquisa (auto)biográfica busca compreender e apreender modos de "ver/ escutar/narrar a vida e as aprendizagens-experienciais" (SOUZA; MEIRELES, 2018, p. 285), ao assumirmos os memoriais de formação (PASSEGGI, 2010b) de educadores da saúde como dispositivo de pesquisa-formação. O memorial de formação configura-se como uma prática de formação centrada na escrita reflexiva e (auto)biográfica no campo da formação inicial ou continuada, o que implica colocar o sujeito em transação consigo mesmo e com disposições temporais, de reflexividade biográfica e de escrita das experiências como férteis para outras compreensões sobre a formação, notadamente, de educadores em saúde.

Os memoriais de formação permitem a sistematização das narrativas, envolvem a escrita, expressando graficamente sua história, através de processos de leituras e releituras, manuseio de tecnologias e escolhas sobre o que se deseja narrar (PASSEGGI, 2010a). Se diferencia da narrativa oral espontânea sobre a própria vida, acessa o pensamento e linguagem, a autocrítica, a interpretação temporal dos contextos históricos e culturais, implicando num movimento de autoria e de reconstrução identitária.

A construção de narrativas de formação caracteriza-se como experiência formadora, pois possibilita que os educadores questionem suas identidades, ancoradas em "recordações-referências" (JOSSO, 2010) e organizem, através da escrita do memorial, temporalidades e identidades narrativas de sua própria história e experiências de vida-formação-profissão. As recordações-referências voltam-se para as dimensões concretas e visíveis, as imagens sociais e as dimensões invisíveis, emoções e valores que se articulam com o processo de reflexividade (auto)biográfica de escrita de si. As narrativas de formação possibilitam reflexões e embates entre o passado e o futuro, implicando questionamentos sobre o tempo presente e sobre modos como os sujeitos refiguram sua identidade narrativa, através da escrita do memorial. 
As narrativas dos educadores da saúde situam-se em um tempo biográfico (DELORY-MOMBERGER, 2012), possibilitando aos coletivos e sujeitos em formação percepções outras sobre a docência e a compreensão do papel de educadores em saúde, mediante elaborações em conexão com sua vida pessoal, profissional e social com o curso de especialização, entrelaçando situações e contextos que tocavam suas vidas, no que se refere à trajetória pregressa pessoal como educando, profissional de saúde e educador.

A análise dos memoriais de formação de três preceptores, na condição de educadores em saúde, remete-nos a discutir movimentos concernentes aos contextos de inserção e de formação dos educadores da saúde, processos de acompanhamento e mediação da escrita narrativa em memoriais de formação, estranhamentos implicados no ato de lembrar e narrar a vida, narrativas sobre percursos formativos e reconhecimento de educadores em saúde, reflexões de processos formativos em conexão com a vida e, por fim, diálogos conclusivos concernentes aos contextos, narrativas e formação em saúde.

\section{Contexto de inserção e de formação dos educadores da saúde}

A identidade docente na saúde vem sendo construída após o ingresso na função de educador. A discussão sobre a carência de espaços de formação de educadores da saúde retratada pelas teses recentes (RAMOS, 2018; CARNEIRO, 2018; SILVA, 2017; LOTTERMANN, 2016; BORBA, 2017; PIO, 2017) registrou percursos de formação voltados prevalentemente à prática clínica na graduação em saúde e à pesquisa em especialidades clínicas nos cursos de pós-graduação stricto sensu - mestrados e doutorados. Os educadores da saúde iniciam suas buscas por formação pedagógica através de investimentos individuais ou em poucas iniciativas das instituições de ensino em que atuam.

São denominados e reconhecidos como preceptores os educadores responsáveis pela formação de trabalhadores do SUS. Estão inseridos nos serviços de saúde e associam à sua prática clínica cotidiana a função de educadores de outros trabalhadores de graduação ou pós-graduação. Os trabalhadores em formação acompanham o preceptor durante a execução de atividades de cuidado associadas a atividades de estudo e pesquisa, numa intensa integração entre ensino e serviços de saúde.

Os Programas de Residências em Saúde compõem a modalidade de pós-graduação latu sensu, são muito valorizados e considerados como alto padrão de qualidade na formação de trabalhadores da saúde desde a década de 
1970 no Brasil. Têm duração mínima de dois anos e carga horária de 60 horas semanais, com um sistema de financiamento de bolsas nacional e processos seletivos concorridos para o ingresso.

Os educadores-preceptores que compõem os Programas de Residências são trabalhadores inseridos nos serviços de saúde do SUS, com experiência reconhecida e titulação mínima de especialistas nas áreas dos programas de residência em que atuam. O ingresso na preceptoria no SUS acontece frequentemente através de convites diretos de coordenadores e instituições de ensino (MATTOS, 2016; ARNEMANN, 2017; SILVA, 2017), sendo raras as experiências de processos seletivos para a função. São raras ainda no Brasil as experiências de remuneração específica para o exercício da preceptoria, sendo cumulativa a atribuição de educador à atribuição prévia na assistência.

O contexto de formação nos Programas de Residências é rico em oportunidades de reflexão sobre o vivido e convida constantemente a olhar para si e suas práticas de cuidado na interlocução com as pessoas assistidas nos serviços de saúde. As histórias de vida singulares, os contextos socioeconômicos, históricos, culturais, psicológicos, atravessam e se interconectam com as histórias de saúde e doença que são compartilhadas diariamente pelas pessoas que procuram os serviços de saúde. Assim, as práticas de saúde vão além dos procedimentos clínicos e tecnologias duras, envolvem uma complexidade de análises, ofertas de cuidado e negociações entre trabalhadores da saúde e a população, o que, consequentemente, torna o contexto de formação propício para se colocar em análise e reinvenção permanente de si.

São crescentes as experiências nacionais de utilização de portfólios reflexivos e memoriais de formação como oportunidade de elaboração sobre o vivido em conexão com as aprendizagens proporcionadas na trajetória dos cursos da saúde, a exemplo do curso desenvolvido pelo Instituto de Ensino e Pesquisa do Hospital Sírio Libanês (OLIVEIRA et al., 2017) que já possibilitou a formação de mais de 5500 educadores, entre 2015 e 2020 , que atuam na preceptoria e coordenação de programas de residências médicas e multiprofissionais no SUS em diversas especialidades, em diversos estados e municípios brasileiros.

As narrativas apresentadas neste artigo registraram trajetórias de formação e experiências de três educadores da saúde - uma cirurgiã dentista, um enfermeiro e um professor de Educação Física - inseridos no curso de especialização em Educação na Saúde para Preceptoria no SUS desenvolvido em 2017 e que atuavam como preceptores no Programa de Residências da Fesf-SUS na Bahia, Brasil.

Por se tratar de narrativas produzidas previamente com objetivos educacionais estritamente, os pesquisadores fizeram contato com os três educadores, solicitando autorização para a utilização dos memoriais, explicitando que esta seguiria os critérios da ética em pesquisa em Ciências Humanas e 
Sociais conforme resolução $N^{\circ}$ 510/16 (BRASIL, 2016) do Conselho Nacional de Saúde (CNS), que a participação seria voluntária e não haveria riscos ou prejuízos aos educadores, bem como foi explicitado o objetivo da pesquisa, possíveis benefícios para a produção de conhecimentos na área da educação e saúde, além da garantia de sigilo sobre a identidade.

\section{Papel do formador: acompanhamento, mediação biográfica e escrita de si em memoriais de formação}

O memorial de formação é compreendido como dispositivo de apreensão e interpretação das vivências, registros sobre a elaboração das aprendizagens experenciais durante o percurso de formação de educadores da saúde (OLIVEIRA et al., 2017), sendo atividade transversal ao período de aproximadamente um ano e produto final de conclusão do curso de especialização em Educação na Saúde para Preceptoria no SUS.

As orientações da formadora sobre a escrita do memorial envolveram a solicitação de registros semanais, em que os educadores foram estimulados a escrever em primeira pessoa e registrar de maneira sincera como se sentiam nas situações, como se constituíam no papel de educadores e o que era possível rever em suas práticas, produzindo potencialmente compromissos de deslocamento consigo mesmos.

Foram utilizadas as seguintes perguntas disparadoras: "O que vejo?"; "O que sinto e penso sobre o que vejo?"; e "O que faço com o que eu sinto e penso sobre o que vejo?" (EPS EM MOVIMENTO, 2014). Essas questões deveriam incluir a realidade vivida cotidianamente como educador em associação às vivências e aprendizados do curso de especialização, fazendo conexões especialmente entre esses dois contextos. Ampliar a narrativa sobre as atividades desenvolvidas (o que vejo), incluindo a crítica reflexiva sobre as atividades desenvolvidas (o que penso sobre o que vejo), a autoavaliação permanente dos educadores e a possibilidade de rever estratégias práticas na relação com os educandos-residentes sob sua responsabilidade (o que faço com o que eu sinto e penso sobre o que vejo).

Durante a produção das narrativas, foi estimulado ainda que os preceptores identificassem lacunas de conhecimento que limitavam sua prática como educadores. Ao fazer o movimento de reflexão sobre sua própria realidade, os desafios e potências que cercavam o seu fazer cotidiano, sentiam-se instigados a procurar respostas que pudessem apoiá-los na qualificação das práticas 
educativas e do cuidado em saúde. Assim, os espaços pedagógicos do curso apoiavam a busca de referenciais teóricos e outras experiências sistematizadas que pudessem dialogar com suas inquietações.

A primeira narrativa solicitada no primeiro encontro do curso foi sobre sua trajetória formativa pregressa até o momento de ingresso no curso. Esperava-se demarcar uma "linha de base" sobre as compreensões dos educadores sobre seus próprios percursos de vida em conexão com seus processos singulares de formação até assumirem a função atual de educadores no contexto do Programa de Residências.

O processo de acompanhamento da escrita das narrativas e mediação da formadora junto aos educadores envolvia encontros individuais, mensais ou a cada dois meses, agendados segundo a necessidade de diálogo dos educadores sobre seu processo de escrita. O encontro tinha curta duração e baseava-se na escuta da formadora sobre o que cada educador desejava apresentar: os avanços na escrita dos memoriais. As perguntas surgiam durante o diálogo a partir das seleções narradas por cada educador e tinham o objetivo de ampliar o movimento reflexivo de autoria. Sobre os processos de autoria, Passeggi e Cunha (2013, p. 46) afirmam que são “[...] narrativas autobiográficas, o autor (consciente ou inconscientemente) escolhe, seleciona, organiza os fatos num enredo, gerencia e adapta esse enredo, transformando crenças e valores pela reflexão, dando sentido ao que antes não tinha $[\ldots . .$. ".

Assim, compreendemos o processo de acompanhamento (PINEAU, 2002; 1998) e mediação na relação entre formadores e educadores como um movimento constante e contínuo de escuta sensível e acolhedora quanto às aprendizagens experenciais singulares, implicando apoio aos educadores em seu percurso de escrita, através do diálogo e problematização sem julgamentos ou prescrições. $\mathrm{O}$ encontro entre formadora e educadores é uma oportunidade de rever, falar, refletir e reelaborar suas experiencias e registros, bem como da possibilidade (auto) formativa vinculada aos processos de escritas de si e de reflexividade biográfica.

A noção de acompanhamento e suas relações com a pesquisa (auto) biográfica emerge do movimento francófono das histórias de vida em formação, possibilitando-nos compreender que acompanhar, no contexto da formação de formadores, vale-se de princípios epistemológicos das histórias de vida em formação e significa caminhar com, partilhar experiências, participar do desenvolvimento ou reinserção profissional através de mediações não diretivas sobre a história e singularidade do adulto em constante aprendizagem e formação.

As aproximações entre acompanhamento (PINEAU, 1998; 2002) e trabalho biográfico (DELORY-MOMBERGER, 2004; 2008) fazem-se a partir do trabalho de mediação das práticas de formação e (auto)formação vividas pelos sujeitos em seus percursos de vida-formação. Para Pineau (1998), a noção de acompanhamento 
vincula-se a uma dimensão antropológica, na medida em que, a partir da palavra oral ou escrita - $\mathrm{o}$ adulto em formação interroga-se sobre condições profissionais e existenciais, buscando outros sentidos para sua vida-formação.

Ao final do curso de especialização, foi solicitado que cada educador fizesse uma releitura e uma análise de suas narrativas, buscando encontrar recorrências, núcleos de sentido e pontos mais mobilizadores relacionados a sua trajetória de vida-formação. A partir da análise, deveriam reorganizar e complementar suas narrativas, se achassem necessário, a partir de novos aprendizados decorrentes da socialização das experiências e do exercício reflexivo e analítico sobre suas próprias histórias e trajetórias formativas. Assim, cada educador produziu um memorial de formação, com a produção de um texto final organizado a partir de seções livremente intituladas e que marcavam aprendizagens experienciais construídas ao longo da vida e da formação-profissão.

\section{Modos de dizer-se e fazer-se educador em saúde: estranhar, formar e formar-se}

Ao analisarmos os memoriais escritos por três preceptores no ano de 2017, no contexto do Programa de Residências da Fesf-SUS na Bahia, no curso de especialização em Educação na Saúde para Preceptoria no SUS, tomaremos como corpus de análise três memoriais construídos por uma cirurgiã dentista, um enfermeiro e um professor de Educação Física, na condição de preceptores. Três eixos temáticos mobilizam nossas reflexões sobre o processo de escrita dos memoriais e as implicações formativas para os três colaboradores. O primeiro eixo volta-se para a discussão de questões de "estranhamentos iniciais do ato de narrar a vida"; o segundo insta-nos a pensar sobre as relações entre "narrativas, percursos formativos e reconhecer-se como educador"; e o terceiro ancora-se em "reflexões sobre o processo formativo em conexão com a vida". Os eixos temáticos emergiram do exercício de escrita, do acompanhamento e mediação biográfica, da escuta atenta e de processos de leituras e releituras dos memoriais, possibilitando-nos inferências compreensiva-interpretativa (SOUZA, 2014) dos percursos de vida-formação dos preceptores, educadores em saúde.

As primeiras narrativas registraram brevemente aspectos relacionados às trajetórias de vida, formação e trabalho. Ao narrarem experiências prévias, os educadores manifestaram um primeiro estranhamento com o formato do memorial e refletiram sobre suas dificuldades em escrever livremente o que pensavam e sentiam sobre o vivido, o mundo da vida. Sobre essa questão, o memorial de E1 evidencia que: 
Antes de começar a minha narrativa reflexiva, confidencio que não foi uma tarefa fácil narrar os fatos vividos, desprender-me dos formatos tradicionais e que nos aprisionam em um modelo que não nos permite ser criativos e livres para escrever como sujeitos, no singular da palavra, transmitir o ritmo, o tom e as emoções que estão em jogo no que está sendo relatado. A reflexão? Estou mudando minha forma de pensar e neste exercicio, reinventando-me e atualizando minhas lembranças como educando e educador, repensando minhas práticas. O que descobri? As lembranças não permanecem intactas porque nós também mudamos, afinal somos sujeitos históricos, inacabados como dizia Paulo Freire (2002), e mais do que isso, sujeitos que estão continuamente escrevendo e reescrevendo sua história $(\mathrm{E} 1)$.

O excerto da narrativa do memorial de E1 demarcar a descoberta pelo educador sobre a importância da escrita e as dificuldades vinculadas inicialmente à escrita do memorial. Registra a percepção de que suas interpretações atuais fazem parte de um contexto histórico, social e político, são atravessadas por um conjunto de representações e crenças construídas coletivamente e individualmente que estão em constante transformação, sendo, portanto, um "retrato" (DELORY-MOMBERGER, 2012) sobre o que pensa nesse momento e nesse contexto específico.

O educador recorda momentos anteriores de sua formação e ressignifica o modelo de educação que considera o ter "aprisionado", ao não permitir sua criatividade e liberdade para narrar o que pensa e sente. A possibilidade de uma formação crítica acontece quando o educador sai de uma posição meramente de transferência de saberes, de impor uma memorização de conteúdos e possibilita que os educandos assumam o protagonismo por seu aprendizado. "O educador democrático não pode negar-se o dever de, na sua prática docente, reforçar a capacidade crítica do educando, sua curiosidade, sua insubmissão" (FREIRE, 2000, p. 26). Assim, os memoriais de formação podem apoiar o educador a revisitar suas referências pessoais, no sentido de refazer sua história como educando e como educador, na interação com seus educandos, apoiá-los a falar, escrever e a libertar-se de possíveis amarras para expressarem-se.

No que se refere à fertilidade das narrativas, suas relações com percursos formativos e movimentos de reconhecer-se como educador, destacamos que as origens e motivações sobre a escolha por uma profissão na saúde e o caminho até se tornar educador são demarcados no exercício inicial das narrativas. A implicação é perceptível e determinante na decisão por ocupar o espaço atual, como pode ser observado no excerto da narrativa de E2, quando afirma que: 
Resolvi fazer um curso na área da saúde por acreditar no potencial do cuidado: uma trilha criativa para um serviço de saúde capaz de transformar, reposicionar o ser humano e o seu entorno. Um recriar-se. $O$ cuidado de uns para com os outros. Valores e saberes tradicionais, ancestrais, articulados aos novos conhecimentos e tecnologias, de maneira compartilhada, coletiva e pública.

No entanto, mediante esse sonho percebi-me inadequada ao longo da graduação em Odontologia [...] Apesar de ter me inserido no Núcleo de Pesquisa Integrada em Saúde Coletiva (NUPISC) durante a graduação e ter professores defensores da Saúde Coletiva e do SUS, no jogo das forças, expressas nos micro comportamentos dos discentes e docentes, havia muito mais uma reprodução de uma formação e de um trabalho em saúde fragmentado e voltado para uma relação do mercado privado. Era uma necessidade minha extrapolar esse circuito de formação em saúde, ir além dos paradigmas da educação bancária que me impunha um padrão reprodutor de uma lógica social que não partilho, e de uma lógica de existência em sociedade que não eram suficientes para produzir-me sentido. Cheguei a transitar pela Pedagogia, Filosofia e em determinado momento me 'distanciar' das Ciências da Saúde pensando ser esse um caminho sem volta. Foi então que tive a oportunidade de ingressar no Programa de Residência Multiprofissional e Médica em Saúde da Família pela Fundação Estatal Saúde da Família (FESF-SUS), vinculada à Fundação Oswaldo Cruz (Fiocruz) e Ministério da Saúde (MS) (E2).

A formação de trabalhadores da área saúde vem passando por transformações, impulsionadas pelas novas diretrizes curriculares dos cursos da saúde (BRASIL, 2001), e investimentos na recondução dos projetos para que contemplem a formação para a promoção, prevenção, recuperação, reabilitação da saúde, a humanização, formação generalista e ampliação da autonomia para aprender.

Os cursos de graduação e pós-graduação da saúde atualmente vivenciam um momento de transição de paradigmas conceituais e práticos, seja nas concepções do campo da saúde quanto da educação. A prática de educadores é permeada pela reprodução de práticas educacionais contraditórias (DAMIANCE, 2016) entre a valorização do cuidado biológico individual - concepção reducionista da saúde - versus o cuidado como intervenção coletiva e individual sobre os resultantes dos modos de vida e trabalho da população - concepção ampliada de saúde -; entre práticas pedagógicas prescritivas, verticalizadas, centradas no docente e com desarticulação entre teoria e prática versus as práticas emancipatórias com estímulo à crítica reflexiva voltada à ação e a novas práticas dela decorrentes. 
Ao final da graduação que decidi fazer a Residência Multiprofissional em Saúde da Família (RMSF), tentei em muitos programas e passei na seleção da Faculdade de Ciências Médicas [...]. Tive a oportunidade de compor um Núcleo de Apoio a Saúde da Família (NASF) com 7 diferentes núcleos profissionais: Psicologia, Nutrição, Fisioterapia, Fonoaudióloga, Terapia Ocupacional, Serviço Social, e Educação Física. Além de uma equipe mínima completa com Médico, Cirurgião Dentista e Enfermeiro, nas Unidades de Saúde da Família (USF) do [...]. Durante a residência foi um momento de descobrir um novo mundo. Uma diversidade de programas em saúde, possibilidade de oferta no qual nem se quer tinha ouvido falar durante a graduação.

Um momento apaixonante em minha trajetória profissional. Possibilidades que encaixam com o pensamento de gerar equidade, e um aprendizado mútuo entre usuário que sabe o que quer e profissional disposto e disponivel a auxiliá-lo nessa busca (E3).

Os educadores que narraram suas experiências são egressos de outros programas de residências ou do próprio programa em que agora assumem um novo papel, passaram de educandos a educadores em poucos anos. As narrativas remetem à influência desse percurso, à implicação e à motivação em se qualificar, ao passo que também fica evidente o quanto é desafiadora a mudança de posição num mesmo contexto de trabalho, produzindo um intenso processo de autoavaliação, afetações e aprendizados significativos.

Encontrar-me em uma residência junto a pessoas abertas para criticar e refletir seus processos de ensino-aprendizagem-serviço (ativamente) contribuiu para o repensar a minha formação como permanente e centrada na integralidade do cuidado em saúde no SUS em seu caráter ético e político. O convívio lado a lado de outros (usuários e profissionais de saúde) com os quais é possivel enfrentar conjuntamente as dificuldades das instituições e serviço de saúde faz da alteridade o aspecto mais transformador e desafiador na formação de profissionais para construir e atuar no SUS, e eu desejo permanecer sendo parte desse processo. Agora no lugar de preceptoria novos desafios são apresentados para mim. Como neste outro lugar posso ser uma agente transformadora dessa lógica de cuidado mecanizada e de uma educação de reprodução? Como na prática do ensino-serviço posso subverter e contribuir para a construção do meu primeiro sonho de cuidado? Faz sentido, pois esse sonho não é apenas meu, mas de muitos! (E2). 
Esse novo desafio me fez perceber a fragilidade que é a função de preceptor e de como eu muitas vezes me via sem saber se estou ajudando os residentes a se desenvolver ou se estou podando esse crescimento. Essa fragilidade ficou cada vez mais evidente nos espaços de formação do corpo pedagógico da Residência da FESF (E3).

A discussão sobre o papel do preceptor no contexto das residências em saúde aponta para a constituição de um sujeito que deve agregar múltiplos fazeres, o que fatalmente impõe uma tensão para que consiga corresponder a tantas necessidades que a realidade apresenta. Se antes o profissional tinha unicamente a responsabilidade por um território e o cuidado das pessoas, o que já era pesado e complexo para a maioria dos profissionais, ao assumir o papel de preceptor, passou a assumir também a responsabilidade pedagógica pela formação de outros trabalhadores e outras tarefas de gestão do processo educativo e da consequente ampliação da complexidade do próprio serviço de saúde ao agregar mais trabalhadores, visto que:

A função do preceptor de território é ser um educador e um cuidador: ser o responsável pela educação permanente dos profissionais, dentro da perspectiva da promoção da saúde, cuidar do residente na sua formação e atuação no território e das questões referentes à residência; como também cuidar da equipe de saúde em que o residente está inserido (PAGANI; ANDRADE, 2012, p. 105).

Os espaços de escuta e apoio aos educadores que estão se compreendendo nesse novo lugar tornam-se imprescindíveis para a formação desses sujeitos. A institucionalização de espaços de educação permanente pode acolher as inquietações e dúvidas que surgem sobre as ações a serem desenvolvidas e especialmente acolher a necessidade de um espaço reflexivo para a consolidação desses trabalhadores no papel de educadores, fortalecendo as relações entre as pessoas e resultando na qualificação dos processos de formação e cuidado em saúde.

As narrativas voltadas para as reflexões sobre processos formativos em conexão com a vida evidenciam o reconhecimento do papel das emoções. Ao considerá-las e estimulá-las no processo de escrita das narrativas, a formação dos educadores toma outros contornos. Quando afetados por situações mobilizadoras, potencialmente carregam as transformações para todas as dimensões que 
compõem sua vida. As narrativas dos memoriais possibilitam perceber que as mudanças acontecem não só nas experiências da inserção no trabalho, pois as dimensões da vida das pessoas são indissociáveis.

Durante o curso consegui alcançar competências de uma melhor escuta ao diferente e não imposição da minha posição sobre o outro. Aprendi a avaliar e reavaliar de diversas formas e da importância de entender que cada tipo de avaliação tem um objetivo na formação e no aprendizado. $O$ curso não apenas atendeu as minhas expectativas de repensar e modificar o meu processo de trabalho como as superou já no primeiro mês. O PSUS, depois da minha residência, foi onde mais me encontrei como pessoa e profissional. Ainda não tinha feito um curso que me modificasse tanto em diversos aspectos da minha vida como aluno, professor ou profissional do NASF junto aos usuários, alunos e colegas de trabalho sejam ele da gestão de nivel universitário ou não. As diversas formas de abordagem para qualquer tema da vida, levando em conta as experiências previas estão cada vez mais internalizadas nas minhas sinteses e nova sintese do conhecimento (E3).

A adoção do dispositivo da narrativa, ancorada nas escritas de si nos memoriais de formação, demarca fertilidades para a refiguração da identidade narrativa do preceptor-educador em saúde, bem como interações entre educadores e educandos, produzindo movimentos de "ondas" progressivas de reposicionamentos e ressignificações desses sujeitos que, nesse contexto relatado, posicionaram-se favoravelmente à implantação de outro modelo de saúde e educação, disponibilizando-se e abrindo-se às mudanças individuais e coletivas no campo da formação e do exercício profissional, na condição de educadores em saúde.

\section{Diálogos (in)conclusivos: contexto, narrativas e formação em saúde}

O contexto atual do Brasil fatalmente influencia e desacelera as mudanças que até o ano de 2016 estavam progressivamente avançando na formação em saúde. O contexto do golpe jurídico parlamentar que vem produzindo intensa instabilidade política e institucional no Brasil, sucedida por uma eleição cercada de muita violência, manipulação e fraude virtual, associada a uma intensa crise 
econômica e mais recentemente à grave crise sanitária com a pandemia do Covid-19, afeta a saúde e a educação com restrições financeiras para manutenção dos serviços de saúde do SUS e das universidades públicas, com cortes de recursos implementados de maneira mais intensa a partir de 2019. Esses fatores vêm produzindo um clima de insegurança e instabilidade também em todos os projetos recém-implementados na última década. Como um dos exemplos mais contundentes, destacamos o Programa Mais Médicos (BRASIL, 2013), que impõe um retrocesso não só no provimento de profissionais médicos em todas as regiões do país, resultando em uma perversa desassistência às populações mais vulneráveis, mas também desestabiliza a complexa política de formação em saúde que estava articulada ao eixo de formação dessa política nacional, incluindo a expansão e oferta de bolsas para os programas de residência em saúde em medicina de família e comunidade e multiprofissional em saúde da família, áreas que são cruciais para reverter o modelo de atenção e educação na saúde, e que retomam o aprendizado prático em comunidade e domicílio em contextos reais da vida das pessoas.

É fundamental ainda a compreensão sobre a práxis dos educadores da saúde que continuam atuando nos serviços de saúde do SUS, ou seja, compreender o processo de problematizar a realidade, buscar soluções, transformar a realidade com sua própria ação e ao mesmo tempo se transformar, exercer uma consciência crítica a partir da dialética subjetividade-objetividade, uma práxis libertadora (FREIRE, 1987, p. 27). Como esses educadores se constituem? Como constroem suas identidades? Quais as possibilidades de formação em suas trajetórias de vida? Como têm se constituído os movimentos singulares de formação em diálogo com as ofertas institucionais das políticas públicas de formação de docentes do último período, conectadas ao contexto social da contemporaneidade?

Ao discutir sobre a influência do Estado na fabricação de identidades de professores, Lawn (2001) afirma que legislações e normas determinam as reorientações das políticas educacionais em diferentes períodos históricos e impactam sobre as identidades e formas de regulá-las. Situa o autor alguns aspectos envolvidos na construção e manutenção de identidades, dentre eles: o crescimento do número de professores, a instabilidade social decorrente de baixas remunerações, o fortalecimento de uma imagem de exemplo moral e servil, a crescente regulamentação, o controle e a cobrança de eficiência no processo de trabalho. A existência de um padrão discursivo sobre o que é ser um professor ideal, em cada período, está conectada ao projeto nacional a ser implementado. Ao mesmo tempo em que as políticas educacionais tentam padronizar e policiar o discurso, inegavelmente os professores possuem seu espaço de poder local, dentro da escola, na sala de aula, nos serviços de saúde, na sociedade. A ideia 
de professores que não se adequam às “identidades oficiais” causa desconfiança, como, por exemplo, o envolvimento de professores aos movimentos sociais. De "profissional colonizado", mais submisso e "neutro", a "profissional moderno", até o professor que corresponda à ideia do desempenho, individualização e liderança que circulam nos tempos mais recentes, as identidades continuam em disputa e fortemente influenciadas pelo Estado e a competitividade imposta pelo sistema capitalista.

A dimensão da construção de identidades pela perspectiva dos educadores da saúde no contexto das políticas públicas de formação de preceptores para o SUS, atrelada à compreensão sobre as condições de trabalho docente associadas aos movimentos de socialização profissional de preceptores do SUS, pode ser problematizada a partir de três teses apresentadas por Dubar (2012), a saber:

a. Os trabalhadores, independente de cor, gênero, religião, aprendem ofícios durante a vida, são reconhecidos a partir de competências que possam ser certificadas e que permitam conseguir um emprego, sendo esse aprendizado não necessariamente adquirido através de instrução formal em escolas, mas no e pelo trabalho, pelas experiências e competências adquiridas. Esse aprendizado envolve engajamento subjetivo. Os trabalhadores da saúde, ao vivenciar a prática educativa nos serviços de saúde, desenvolvem as competências para a preceptoria e passam a ser reconhecidos socialmente como educadores em seus contextos?

b. A formação profissional não é restrita apenas a uma etapa da vida ou à fase da escolarização. O aprendizado acontece ao longo da vida e é impulsionado pela necessidade de mudança de ofício, profissão ou emprego, além das imposições colocadas por novas tecnologias e políticas públicas ou de grandes empresas. A formação no trabalho passou a ser tão importante quanto a formação inicial de trabalhadores. Acompanhando essa segunda tese, destacamos a concepção da educação permanente em saúde que tem sustentado uma mudança de paradigma na formação em saúde, seja na prática de preceptores junto a outros trabalhadores, seja na formação pedagógica dos preceptores, uma concepção que reconhece e valoriza as "[...] competências relacionais, de aprendizagem da reflexividade no trabalho [...]" (DUBAR, 2012, p. 365);

c. As etapas de formação associadas ao trabalho, seja em forma de estágios ou outros nomes designados a esse ingresso em profissões ou carreiras através de um período inicial de baixas remunerações ou até com ausência temporária de salários, têm sido cada vez mais comuns em diversas áreas e em diversos países. É importante considerar que existe uma diversidade de organização dos empregos, formação profissional e de carreiras, associada a diferentes tradições sociais e regimes políticos. Na saúde, no Brasil, no contexto específico das residências em saúde, acumula-se uma larga experiência na diferenciação dessa primeira etapa profissional, associando o trabalho à formação em serviço, 
porém com diversas especificidades que serão exploradas no decorrer desta pesquisa, mas que não permitem a ausência da remuneração, com um sistema nacional de bolsas financiado prioritariamente pelo governo federal, através dos ministérios da saúde e da educação, além de secretarias estaduais e municipais de saúde. Nesse caso, o que vale a pena explorar ainda, é a polêmica sobre a remuneração específica para o exercício da preceptoria, quando o trabalhador da saúde ingressa como educador, acumulando novas atividades dentro dos serviços de saúde. Existem diferentes experiências no país, desde a ausência de remuneração específica até a valorização da preceptoria com o pagamento de bolsas, gratificações e adicionais.

As condições de trabalho docente podem ser compreendidas de maneira ampliada, considerando o processo de trabalho num determinado contexto histórico-social e econômico, para além dos recursos objetivos, estruturais ou físicos necessários para o desenvolvimento do trabalho, mas também as condições de emprego como relações contratuais, remuneração, estabilidade, além das condições de vida decorrentes. Interessa ainda compreender nas condições de trabalho docente na saúde o sentido que atribuem ao trabalho educativo associado ao trabalho de cuidado em saúde, as relações de satisfação a partir dos investimentos e possibilidades de desenvolvimento em seu contexto. Compreender ainda as relações entre empregador e empregados, intensificação do trabalho, precarização, possíveis riscos, constrangimentos e pressões, presentes comumente nas condições de trabalho da sociedade capitalista (OLIVEIRA; ASSUNÇÃO, 2010).

Reconhecer ainda os processos de fortalecimento e desgaste constitutivos da esfera da reprodução social. A compreensão do objeto da saúde coletiva, com a análise sobre os perfis de reprodução social e os de saúde-doença, nos permitem também ampliar a leitura sobre as condições de trabalho, ao passo em que as formas de trabalhar e consumir, a maneira como produzem e distribuem seu trabalho socialmente, as formas de organização, relações estabelecidas entre as pessoas para produzir a vida social, o pertencimento de classe social e os modos de vida articulados são elementos que precisam ser levados em consideração nas expressões biopsíquicas da história individual de cada docente (VIANA; SOARES; CAMPOS, 2013).

Ao analisarmos historicamente a formação em saúde (PADILLA, 2020), podemos perceber que os movimentos de disputa instaurados especialmente durante o último século e intensificados na última década no Brasil caminhavam para a restauração de princípios de uma formação humanística, de um aprendizado que valoriza a experiência, que transcende a doença, que defende a vida e as relações humanas, a saúde como um direito universal. 
A formação na saúde tem acompanhado as revoluções e contrarrevoluções da história da educação. A criação de sistemas escolares a serviço da burocracia estatal, da religião e da indústria também determinou a formação de trabalhadores da saúde com o intuito de adestrar e controlar os corpos para o trabalho. O capitalismo foi o fator mais poderoso de intervenção sobre a escola e tem sido fator determinante na disputa de concepções sobre saúde e das práticas educativas na saúde.

No cenário atual de tantas incertezas sobre os desdobramentos possíveis da atual pandemia do Covid-19, é latente a dúvida sobre as transformações na formação em saúde. Os retrocessos recentes no financiamento e nas políticas de educação e saúde no país inevitavelmente determinarão um refluxo dos movimentos progressistas, a resistência e o engajamento político de gestores e educadores que assumiram o desafio de instituir novos espaços de educação outrora é o que resta em momento de tamanha crise mundial e nacional.

\section{REFERÊNCIAS}

ARNEMANN, Cristiane Trivisiol. Educação permanente em saúde no contexto da residência multiprofissional: estudo apreciativo crítico. 2017. Tese (Doutorado em Enfermagem) - Programa de Pós Graduação em Enfermagem, Universidade Federal do Rio Grande do Sul, Porto Alegre, 2017.

BORBA, Kátia Pereira de. Desenvolvimento profissional docente: um estudo com professores enfermeiros universitários. 2017. Tese (Doutorado em Enfermagem) - Escola de Enfermagem, Universidade de São Paulo, Ribeirão Preto, 2017.

BRASIL. Lei no 12.871, de 22 de outubro de 2013. Institui o Programa Mais Médicos, altera as Leis n. 8.745, de 9 de dezembro de 1993, e n. 6.932, de 7 de julho de 1981, e dá outras providências. Diário Oficial da União, Brasília, n. 206, p. 1-4. 23 out. 2013. Seção 1. Disponível em: https://www2.camara.leg.br/legin/fed/lei/2013/lei-12871-22outubro-2013-777279-norma-pl.html. Acesso em: 27 mar. 2020.

BRASIL. Ministério da Educação. Parecer CNE/CES n. 1.133/2001. Diretrizes Curriculares Nacionais dos Cursos de Graduação em Enfermagem, Medicina e Nutrição. Diário Oficial da União, Poder Executivo, Brasília, no 190, p. 131, 3 out. 2001. Seção 1E. Disponível em: http://portal.mec.gov.br/dmdocuments/ces1133.pdf. Acesso em: 27 mar. 2020. 
BRASIL. Ministério da Saúde. Resolução $n^{\circ}$ 510, de 7 de abril de 2016. O Plenário do Conselho Nacional de Saúde em sua Quinquagésima Nona Reunião Extraordinária, realizada nos dias 06 e 07 de abril de 2016, [...]. Brasília, DF: MS, 2016. Disponível em: https://bvsms.saude.gov.br/bvs/saudelegis/cns/2016/res0510_07_04_2016.html. Acesso em: 20 jun. 2020.

CARNEIRO, Marcia Simão. Representações sociais de professores do curso de enfermagem de instituições de ensino superior públicas sobre práticas obstétricas: implicações para a formação docente. 2018. Tese (Doutorado em Educação) - Instituto de Ciências da Educação, Universidade Federal do Pará, Belém do Pará, 2018.

DAMIANCE, Patrícia Ribeiro Mattar et al. Formação para o SUS: uma análise sobre as concepções e práticas pedagógicas em saúde coletiva. Trab. educ. saúde, Rio de Janeiro, v. 14, n. 3, p. 699-721, 2016. Disponível em: https://www.scielo.br/scielo.php?script=sci arttext\&pid=S1981-77462016000300699. Acesso em: 22 jun. 2020.

DELORY-MOMBERGER, Christine. Abordagem metodológica na pesquisa biográfica. Revista Brasileira de Educação, Rio de Janeiro, v. 17, n. 51, p. 523-740, set./dez. 2012. Disponível em: http://www.scielo.br/pdf/rbedu/v17n51/02.pdf. Acesso em: 20 abr. 2020.

DELORY-MOMBERGER, Christine. Biografia e Educação: figuras do indivíduoprojeto. Tradução de Maria da Conceição Passeggi e João Gomes da Silva Neto, Natal: EDUFRN; São Paulo: PAULUS, 2008. Coleção Pesquisa (Auto)biográfica \& Educação.

DELORY-MOMBERGER, Christine. Les histoires de vie. De l'invention de soi au projet de formation. Paris: Anthropos, 2004.

DUBAR, Claude. A construção de si pela atividade de trabalho: a socialização profissional. Cadernos de Pesquisa, São Paulo, v. 42, n. 146, p. 351-367, maio/ago. 2012.

EPS EM MOVIMENTO. Caixa de afecções. [s.l.], 2014. Disponível em: http://eps.otics. org/material/entrada-experimentacoes/caixa-de-afeccoes. Acesso em: 19 maio 2020.

FREIRE, Paulo. Pedagogia do oprimido. São Paulo: Paz e Terra, 1987.

FREIRE, Paulo. Pedagogia da autonomia: saberes necessários à prática educativa. São Paulo: Paz e Terra, 2000.

JOSSO, Marie-Christine. Experiências de vida e formação. São Paulo: Paulus; Natal: EDUFRN, 2010.

LAWN, Martin. Os professores e a fabricação de identidades. Currículo sem Fronteiras, v. 1, n. 2, p. 117-130, 2001.

LOTTERMANN, Karla Siqueira. Trabalho docente em saúde: desafios e perspectivas. 2016. Tese (Doutorado em Ciências da Saúde) - Universidade Federal de Goiás, Goiânia, 2016. 
MATTOS, Tânia Mara Cappi. Ideologia que permeia a prática da educação permanente por tutores e preceptores da residência multiprofissional em saúde. 2016. Tese (Doutorado em Enfermagem) - Escola de Enfermagem, Universidade Federal do Rio de Janeiro, Rio de Janeiro, 2016.

OLIVEIRA, Dalila Andrade; ASSUNÇÃO, Ada Ávila. Condições de trabalho docente. In: OLIVEIRA, Dalila Andrade; DUARTE, Adriana Maria Cancella; VIEIRA, Lívia Maria Fraga. DICIONÁRIO: trabalho, profissão e condição docente. Belo Horizonte: UFMG/Faculdade de Educação, 2010. CDROM.

OLIVEIRA, Marilda Siriani de et al. (org.). Preceptoria no SUS: caderno do curso 2017. São Paulo: Hospital Sírio-Libanês; Brasília, DF: Ministério da Saúde, 2017.

PADILLA, Mónica. Educação e prática interprofissional no Sistema Único de Saúde: práticas compartilhadas e exigências de interação em equipe na saúde. In: FERLA, Alcindo Antônio et al. (org.). Aprender com a prática e atuar em coletivos: interseções ensino e trabalho no escopo da saúde. Porto Alegre, RS: Editora Rede Unida, 2020. p. 08-14.

PAGANI, Rosani; ANDRADE, Luiz Odorico Monteiro de. Preceptoria de território, novas práticas e saberes na estratégia de educação permanente em saúde da família: o estudo do caso de Sobral, CE. Saude soc., São Paulo, v. 21, supl. 1, p. 94-106, maio 2012. Disponível em: http://www.scielo.br/scielo.php?script=sci_arttext\&pid=S0104$12902012000500008 \& \operatorname{lng}=$ pt\&nrm=iso. Acesso em: 27 jun. 2020.

PASSEGGI, Maria da Conceição; CUNHA, Luciana Medeiros da. Narrativas autobiográficas: a imersão no processo de autoria. In: Pesquisa (auto)biográfica: questões de ensino e formação. VICENTINI, Paula Perin; SOUZA, Elizeu Clementino de; PASSEGGI, Maria da Conceição (org.). Curitiba: CRV, 2013, p. 43-57.

PASSEGGI, Maria da Conceição. "Narrar é humano! Autobiografar é um processo civilizatório". In: PASSEGGI, Maria da Conceição; SILVA, Vivian Batista da. Invenções de vidas, compreensão de itinerários e alternativas de formação. São Paulo: Cultura Acadêmica, 2010a, p. 103-130.

PASSEGGI, Maria da Conceição. Memoriais autobiográficos: escritas de si como arte de (re)conhecimento. In: CORDEIRO, Verbena Maria Rocha; SOUZA, Elizeu Clementino de (org.). Memoriais, literatura e práticas culturais de leitura. Salvador: EDUFBA, 2010b. p. 19-42.

PINEAU, Gaston. L'accompagnement en formation: de l'avant-naissance à l'après-mort. Entre solidarité et professionnalité. Education Permanente. L'accompagnement dans tous ses états, Paris, v. 4, n. 153, p. 29-41, 2002.

PINEAU, Gaston. Accompagnements et histoire de vie. Paris: L'Harmattan, 1998.

PIO, Danielle Abdel Massih. A experiência do professor médico com métodos ativos de ensino-aprendizagem: formação permanente e gestão como mediadoras. 2017. Tese (Doutorado em Saúde Coletiva) - Faculdade de Medicina, Universidade Estadual Paulista, Botucatu, 2017. 
RAMOS, Evódio Maurício Oliveira. Professores bacharéis da saúde: trajetórias de profissionalidades docentes. 2018. Tese (Doutorado em Educação) - Centro de Educação. Universidade Estadual do Ceará, Fortaleza, 2018.

SILVA, Verônica Caé da. Os saberes que emergem da prática social do enfermeiro preceptor na residência multiprofissional em saúde. 2017. Tese (Doutorado em Enfermagem) - Escola de Enfermagem, Universidade Federal do Rio de Janeiro, Rio de Janeiro, 2017.

SOUZA, Elizeu Clementino de. Diálogos cruzados sobre pesquisa (auto)biográfica: análise compreensiva-interpretativa e política de sentido. Revista Educação, Santa Maria, v. 39, n. 1, p. 39-50, jan./abr. 2014. Disponível em: https://periodicos.ufsm.br/index.php/ reveducacao/article/view/11344. Acesso em: 24 mar. 2020.

SOUZA, Elizeu Clementino de; MEIRELES, Mariana Martins de. Olhar, escutar e sentir: modos de pesquisar-narrar em educação. Educação e Cultura Contemporânea, Rio de Janeiro, v. 15, n. 39, p. 282-303, 2018. Disponível em: http://periodicos.estacio.br/index. php/reeduc/article/view/4750/47966110. Acesso em: 21 jul. 2020.

VIANA, Nildo; SOARES, Cassia Baldini; CAMPOS, Célia Maria Sivalli. Reprodução social e processo saúde-doença: para compreender o objeto da saúde coletiva. In: SOARES, Cassia Baldini; CAMPOS, Célia Maria Sivalli (org.). Fundamentos de saúde coletiva e o cuidado de enfermagem. Barueri, SP: Manole, 2013. p. 107-142.

Texto recebido em 23/07/2020.

Texto aprovado em 01/09/2020. 